\title{
Monitoring ovarian function and pregnancy by evaluating excretion of urinary oestrogen conjugates in semi-free-ranging Przewalski’s horses (Equus przewalskii)
}

\author{
S. L. Monfort* $\uparrow \S$, N. P. Arthur† and D. E. Wildt $† \ddagger$ \\ $\dagger$ National Zoological Park, Department of Animal Health and the Conservation and Research \\ Center, Smithsonian Institution, Washington, DC 20008, USA; and $\ddagger$ Department of Biology, \\ George Mason University, Fairfax, Virginia 22030, USA
}

\begin{abstract}
Summary. Immunoreactive urinary oestrogen conjugates were assessed in daily urine samples ( $\sim 5$ samples/week) collected from 8 Przewalski's mares maintained under semifree-ranging pasture conditions. The relative percentage contributions of immunoreactive urinary oestrogens during different reproductive states (oestrus, luteal phase, early, mid- and late gestation) were determined using high-pressure liquid chromatography. In general, conjugated forms of oestrone (oestrone sulphate and oestrone glucuronide) were the major excreted immunoreactive oestrogens in nonpregnant and pregnant Przewalski's mares. Variations in urinary oestrogen conjugates indicated that the onset of oestrous cyclicity coincided with increasing daylengths, and the non-conception oestrous cycle was $24 \cdot 1 \pm 0.7$ days $(n=17)$ in duration. Most copulations $(29 / 35,82.9 \%)$ were observed between Day -4 and Day +1 from the preovulatory oestrogen conjugates peak (Day 0). Based on known copulation dates, the mean gestation length was $48.6 \pm 0.4$ weeks (range $47.3-50 \cdot 3$ weeks). During pregnancy, urinary excretion of oestrogen conjugates increased $\sim 300$-fold over levels in non-pregnant mares, reaching peak concentrations by Week +24 (51\% of gestation). These results demonstrate that longitudinal reproductive events, including oestrous cyclicity and pregnancy, can be monitored precisely by evaluating urinary oestrogen conjugates in samples from Przewalski's mares maintained under semi-free-ranging conditions.
\end{abstract}

Keywords: Przewalski's horse; oestrogen; oestrous cycle; pregnancy; urinary steroids

\section{Introduction}

Ancestors of the endangered Asian wild horse or Przewalski's horse (Equus przewalskii) once roamed throughout Central Asia, China and Europe. The species now is extinct in the wild, and remnant populations exist only in small captive breeding herds. Although evolutionary divergence of the Przewalski's and domestic horse (Equus caballus) occurred $\sim 250000$ years ago, the 2 species are capable of interbreeding and producing fertile offspring (Short, 1975). Successful interspecies embryo transfer has also been achieved (Hearn \& Summers, 1986). All living Przewalski's horses are descended from 13 founder individuals, the last of which was captured in Mongolia in 1947 (Bowling \& Ryder, 1987). Although classified as endangered, the Przewalski's horse reproduces

*Address for correspondence: Dr S. L. Monfort, National Zoological Park, Conservation and Research Center, Route 522 South, Front Royal, VA 22630, USA. 
successfully in captivity, and the current population now exceeds 900 individuals. Current management strategies focus on broadening the genetic base by minimizing inbreeding and maximizing the genetic contribution from offspring of each of the original 13 founders (Ryder, 1988).

Behavioural studies suggest that Przewalski's mares are seasonally polyoestrous and they exhibit oestrus in early spring after a seasonal anoestrus during the late fall and winter months (Boyd, 1988). Observational studies suggest that mares have a gestation of $\sim 48$ weeks (Boyd, 1988).

In the domestic horse, the ovarian hormone oestrone is excreted almost exclusively in the urine (Velle, 1963). Consequently, urinary steroid analysis has been useful for documenting reproductive status in this species (Hillman \& Loy, 1975; Palmer \& Jousset, 1975). More recently, radioimmunoassay (RIA) of conjugated urinary oestrogens has been used to assess reproductive activity, including diagnosing pregnancy in domestic (Evans et al., 1984; Lasley et al., 1990) and feral (Kirkpatrick et al., 1988) horses and captive zebras (Czekala et al., 1990). Czekala et al. (1990) have diagnosed pregnancy successfully in the Przewalski's horse by assessing oestrone sulphate concentrations in urine samples collected by catheterization from anaesthetized mares.

To date, longitudinal endocrine cycles in this species have not been monitored, nor is there specific information on oestrogen metabolism. Details on the latter are a mandatory prerequisite for ensuring the utility of urinary RIA procedures for assessing reproductive function. Our objective was to extend the previous findings of others by using a longitudinal approach. Specifically, the present study was conducted to: (1) validate the RIA procedures for assessing urinary oestrogen conjugates in Przewalski's horses maintained under pasture conditions; (2) use this strategy to characterize seasonal rhythms of ovarian activity and copulatory behaviour in nonpregnant mares; and (3) document excretion patterns of oestrogen conjugates to determine the temporal relationships of copulation to first diagnostic evidence of pregnancy.

\section{Materials and Methods}

Animals and sample collections. Urine samples were collected from 3 multiparous and 5 nulliparous mares (2-7 years of age) from May 1987 through November 1988. Mares were maintained with a single stallion in a 12-ha pasture at the National Zoological Park's Conservation and Research Center, Front Royal, Virginia ( $38^{\circ} \mathrm{N}$ latitude). Animals were observed (2-4h/day) at close range from a vehicle, and copulations were recorded. After animals urinated, samples $(1-5 \mathrm{ml})$ were aspirated within $1 \mathrm{~min}$ from urine pooled on the ground. Each sample was centrifuged within $3 \mathrm{~h}(1500 \mathrm{~g}, 10 \mathrm{~min})$ to remove particulate matter and stored frozen $\left(-20^{\circ} \mathrm{C}\right)$ until assayed. Samples were recovered an average of 5 times/week/female throughout the 18-month study period. To compensate for changes in fluid balance, all samples were indexed by creatinine (Cr) measurement (Taussky, 1954; Monfort et al., 1989, 1990), and values were expressed as mass units/mg $\mathrm{Cr}$ excreted. To ensure that data were not compromised from urine samples which may have been diluted by water on the ground, samples with $\mathrm{Cr}_{\mathrm{r}}$ concentrations of $<0.1 \mathrm{mg} / \mathrm{ml}$ were discarded. This criterion eliminated 108 of 1615 collected urine samples $(6 \cdot 7 \%)$.

Assay for oestrogen conjugates. Urinary oestrogen conjugates were analysed by a direct RIA procedure described by Shideler et al. (1983) using an antiserum (R583; B. L. Lasley, Davis, CA, USA) directed against oestrone-3glucuronide $(1: 6000$ dilution, $100 \mu \mathrm{l})$. With oestrone sulphate as a standard $(100 \%)$, this antibody cross-reacts with oestrone $(200 \%)$, oestradiol-17及 $(100 \%)$, equilin $(50 \%)$, oestrone-3-glucuronide $(38 \%)$, oestradiol-3-sulphate $(21 \%)$ and oestradiol-3-glucuronide (6.8\%). Cross-reactivity is less than $0.5 \%$ for all non-oestrogenic steroids tested (B. $\mathbf{L}$. Lasley, personal communication). Urine samples were diluted 1:100 (25 $\mu \mathrm{l}$, non-pregnant mares) and 1:10000 (50 $\mu 1$, pregnant mares) in Tris buffer ( $\mathrm{pH} 8 \cdot 4,0 \cdot 1 \mathrm{M}$-Tris, $0.9 \% \mathrm{NaCl}, 1 \%$ gelatin) and assayed in duplicate. $\left[{ }^{3} \mathrm{H}\right]$ Oestrone sulphate (100 $\mu$; 10000 c.p.m.; sp. act. $60.0 \mathrm{Ci} / \mathrm{mmol}$ : Dupont/New England Nuclear, Wilmington, DE, USA) was combined with standards $\left(4 \cdot 9-1250 \mathrm{pg} /\right.$ tube; in triplicate) and unknowns (in duplicate). After incubation $\left(4^{\circ} \mathrm{C}\right)$ for $3 \mathrm{~h}, 500 \mu \mathrm{l}$ charcoal-Dextran solution $(0.0625 \%$ charcoal, $0.00625 \%$ Dextran in $0.1 \mathrm{M}$-phosphate buffer, $\mathrm{pH} 7.0)$ were added to separate free from antibody-bound steroid. After a 30 -min incubation $\left(4^{\circ} \mathrm{C}\right)$, tubes were centrifuged $(1500 \mathrm{~g}$, $10 \mathrm{~min}$ ), decanted into scintillation vials with $5.0 \mathrm{ml}$ Ready Protein (Beckman Instruments, Inc., Fullerton, CA, USA) and radioactivity counted for $5 \mathrm{~min}$.

Parallel displacement curves were obtained by serial dilutions of pooled oestrous, luteal and early pregnancy $(\sim 40$ days' gestation) urine (1:10 to 1:640) and oestrone sulphate standards. Diluted mid- and late-gestational phase urine (1:400 to 1:100000) also were parallel to the standard curve. The inter-assay coefficients of variation for 3 separate internal controls were $9.0 \%(n=40,20-25 \%$ binding $), 11.0 \%(n=40,50-60 \%$ binding $)$ and $26.0 \%(n=40$, $75-85 \%$ binding). Inter-assay coefficients of variation were $<10 \%$, and assay sensitivity was $4.9 \mathrm{pg} /$ tube. Recovery of 
known amounts of oestrone sulphate (range, $4.9-1250 \mathrm{pg} /$ tube) added to a pool of diluted urine $(1: 100,25 \mu \mathrm{l})$ was $95 \cdot 1 \pm 8 \cdot 1 \%(y=1 \cdot 21+1.06 x, r=0.99)$.

High-pressure liquid chromatography (HPLC). Using pooled urine samples from 2 mares representing different reproductive states (oestrus, luteal phase, early, mid- and late gestation), HPLC was performed to identify the relative contributions of oestrogenic components. The chromatographic system consisted of 2 Rainin Rabbit HP/HPX pumps (Rainin Instruments Co., Woburn, MA, USA) connected to a gradient mixer, a Rheodyne injector (Model 7125 , Berkeley, CA, USA) and a $100 \mu$ l sample loop fitted to a reverse-phase Microsorb ${ }^{\circledR}$ column (RP C-18, $5 \mu \mathrm{m}$ diam. particle size). Fractions were collected with a Gilson FC203 fraction collector (Gilson Medical Electronics Inc., Middleton, WI, USA). Chromatographic grade methanol and water were filtered using nylon-66 filters (47 mm diam., $0.2 \mu \mathrm{m}$ pore size; Rainin Instruments $\mathrm{Co}_{0}$.) and degassed before use.

Before HPLC, undiluted urine samples were pre-processed using reversed-phase C18 cartridges (Spice(i冈M, Analtech, Newark, DE, USA) according to previously reported methods (Heikkinen et al., 1981). Cartridges were pre-conditioned with $5 \mathrm{ml}$ methanol followed by $5 \mathrm{ml}$ de-ionized water. Urine $(0.5 \mathrm{ml})$ was combined with $\sim 1500$ c.p.m. $\left[{ }^{3} \mathrm{H}\right]$ oestrone sulphate (to monitor extraction efficiency) in a 3-ml plastic syringe fitted to a $\mathrm{Cl} 8$ cartridge (containing $400 \mathrm{mg}$ sorbent material/cartridge) and loaded into the cartridge. Oestrogens were eluted in $5 \mathrm{ml}$ methanol, evaporated to dryness under nitrogen gas and reconstituted in precisely $0.5 \mathrm{ml}$ methanol. Mean ( \pm s.e.m.) percentage recovery of tritiated label was $85.7 \pm 1.5 \%(n=6)$. A $0.2 \mathrm{ml}$ portion of the extractant was transferred into a conical vial containing $\sim 6000$ c.p.m. each $\left[{ }^{3} \mathrm{H}\right]$ oestrone glucuronide, $\left[{ }^{3} \mathrm{H}\right]$ oestrone sulphate, $\left[{ }^{3} \mathrm{H}\right]$ oestradiol- $17 \beta$ and $\left[{ }^{3} \mathrm{H}\right]$ oestrone added previously (and taken to dryness) to serve as co-chromatographic markers. A 55 - $\mu$ l portion of the extractant ( 1600 c.p.m./radiolabelled marker) was loaded on to the HPLC column, and a linear gradient of $20-100 \%$ methanol in water within $80 \mathrm{~min}(1 \mathrm{ml} / \mathrm{min}$ flow rate, $1.0 \mathrm{ml}$ fractions) was used to separate oestrogenic components. Separate samples $(200 \mu \mathrm{l})$ of each fraction were counted directly for recovery and assayed for immunoreactivity using the RIA for conjugated oestrogens described above.

Statistical analysis. Statistics were performed using the System for Elementary Statistical Analysis(SAS Institute Inc., Cary, NC, USA) on a Vax 8800 microcomputer. Weekly mean hormone concentrations represent the mean \pm s.e.m. of daily hormone values pooled by week of collection. Statistical differences between grouped weekly hormone concentrations were determined by one-way analysis of variance, and multiple comparisons were made using Duncan's Multiple Range Test and a Student's $t$ test.

\section{Results}

The relative percentage contributions of immunoreactive urinary oestrone, oestradiol, oestrone sulphate, oestrone glucuronide and unknown oestrogenic compounts separated by HPLC are depicted in Fig. 1(a,b). Because oestrone and oestradiol co-eluted in the same fractions, these unconjugated oestrogens were expressed as a combined value. Oestrone/oestradiol, oestrone glucuronide and oestrone sulphate were defined as the immunoreactive peaks which co-eluted with the radiolabelled marker. Unconjugated oestrone/oestradiol $(46.5 \%)$ and conjugated oestrone sulphate $(43.3 \%)$ predominated in the urine of oestrous mares (Fig. 1b), whereas oestrone glucuronide and unknown immunoreactive oestrogenic components were lesser contributors at $10.0 \%$ and $<0.2 \%$, respectively. During the luteal phase, conjugated oestrone sulphate comprised $60.9 \%$ and oestrone/oestradiol, oestrone glucuronide and unknowns accounted for $20 \cdot 2 \%, 18.4 \%$ and $0.5 \%$ of excreted oestrogen immunoreactivity, respectively. By early pregnancy ( $\sim 40$ days' gestation), immunoreactive oestrone sulphate and oestrone glucuronide were excreted in approximately equal proportions and comprised most of the voided oestrogen (total, $90.5 \%$ ) compared to the low contribution of oestrone/oestradiol (5.3\%) and unknown compounds (4.2\%). During midand late pregnancy, clearly immunoreactive oestrone sulphate predominated (mid-, 97.9\%; late, $92.7 \%$ ) over all other components. Figure 1(a) illustrates the relative percentage contributions of unconjugated oestrone/oestradiol compared to the combined total of conjugated oestrone sulphate and oestrone glucuronide. In general, as pregnancy progressed, conjugated oestrone increased markedly with a simultaneous decrease in unconjugated oestrogen excretion.

Based on variations in urinary oestrogen conjugates, onset of oestrous cyclicity coincided with increasing daylengths and, among animals, ranged from February to April. Representative longitudinal oestrogen profiles from 3 mares sampled from January through June are depicted in Fig. 2(b-d). Although 4 mares exhibited cyclic ovarian activity, and copulated early in the 


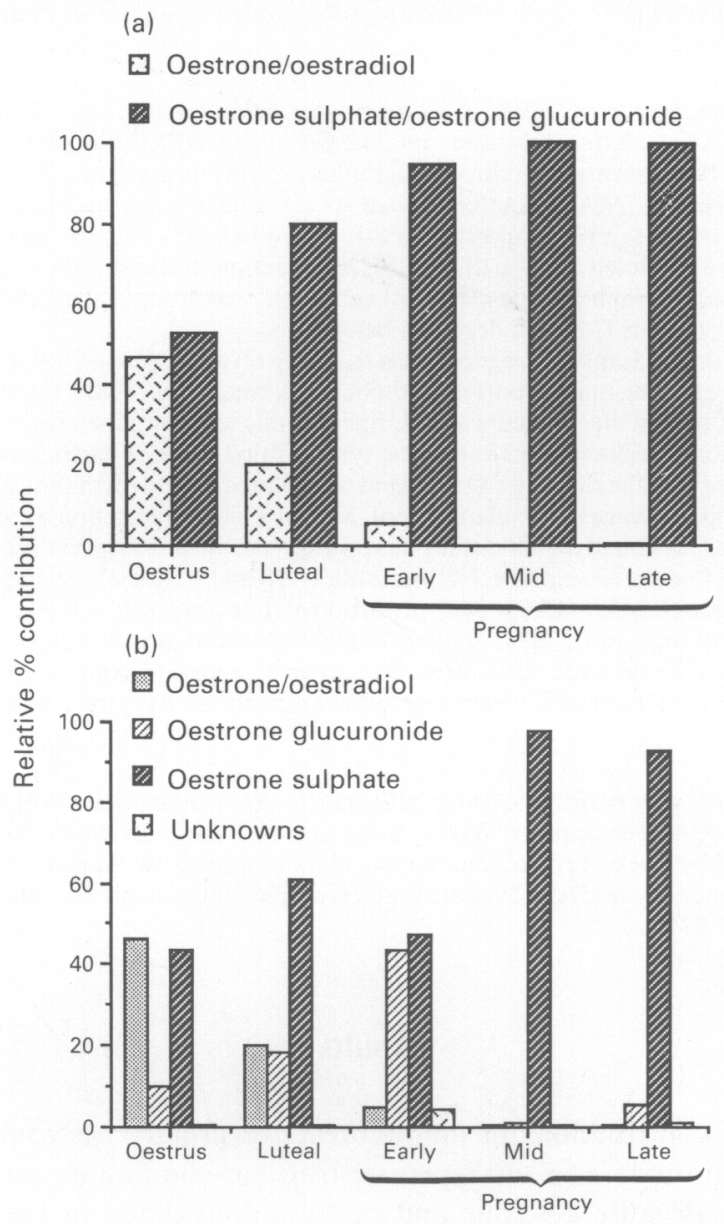

Fig. 1. The relative percentage contribution of immunoreactive urinary oestrogens separated by HPLC.

year (February-March), none of these mares conceived during this time. All conceptions $(n=9)$ occurred in the months of April through November.

Daily mean urinary concentrations of oestrogen conjugates ( \pm s.e.m.) representing 17 nonconceptive oestrous cycles from 6 mares are presented in Fig. 3. All sample data were aligned on the day of the oestrogen conjugates peak (Day 0 ). The interval between consecutive peaks provided an estimated oestrous cycle length of $24 \cdot 1 \pm 0 \cdot 7$ days $(n=17)$. Of 35 observed copulations, $29(83 \%)$ occurred from Day -4 to Day +1 . Beginning on Day -8 , oestrogen conjugate concentrations increased $\sim 7$-fold from basal concentrations $(0.04 \pm 0.02 \mu \mathrm{g} / \mathrm{mg} \mathrm{Cr})$ to a preovulatory peak of $0.29 \pm 0.03 \mu \mathrm{g} / \mathrm{mg}$ Cr (Day $0, P<0.05)$. After an abrupt decline $(P<0.05)$ to $0.10 \pm 0.02 \mu \mathrm{g} / \mathrm{mg}$ $\mathrm{Cr}$ by Day +2 , there was a secondary peak to $0.16 \pm 0.03 \mu \mathrm{g} / \mathrm{mg} \mathrm{Cr}(P>0.05)$ on Day +4 followed by a decline to baseline by Day $+12(P<0.05,0.07 \pm 0.01 \mu \mathrm{g} / \mathrm{mg} \mathrm{Cr})$.

An overall weekly pregnancy composite profile (Fig. 4) was generated from 9 pregnancies ( 7 mares) aligned to the day of parturition (Day 0): 4 mares were sampled throughout pregnancy, 2 were studied during the last third of pregnancy and 3 were monitored only during the first 10 weeks of gestation. Based on known copulation dates for 6 mares, the mean gestation length was $48 \cdot 6 \pm 0.4$ weeks (range, $47 \cdot 3-50 \cdot 3$ weeks), and the mean time of conception was best approximated by Week -49 (Fig. 4 inset; $0 \cdot 16 \pm 0.01 \mu \mathrm{g} / \mathrm{mg} \mathrm{Cr}$ ). During early pregnancy, mean oestrogen 

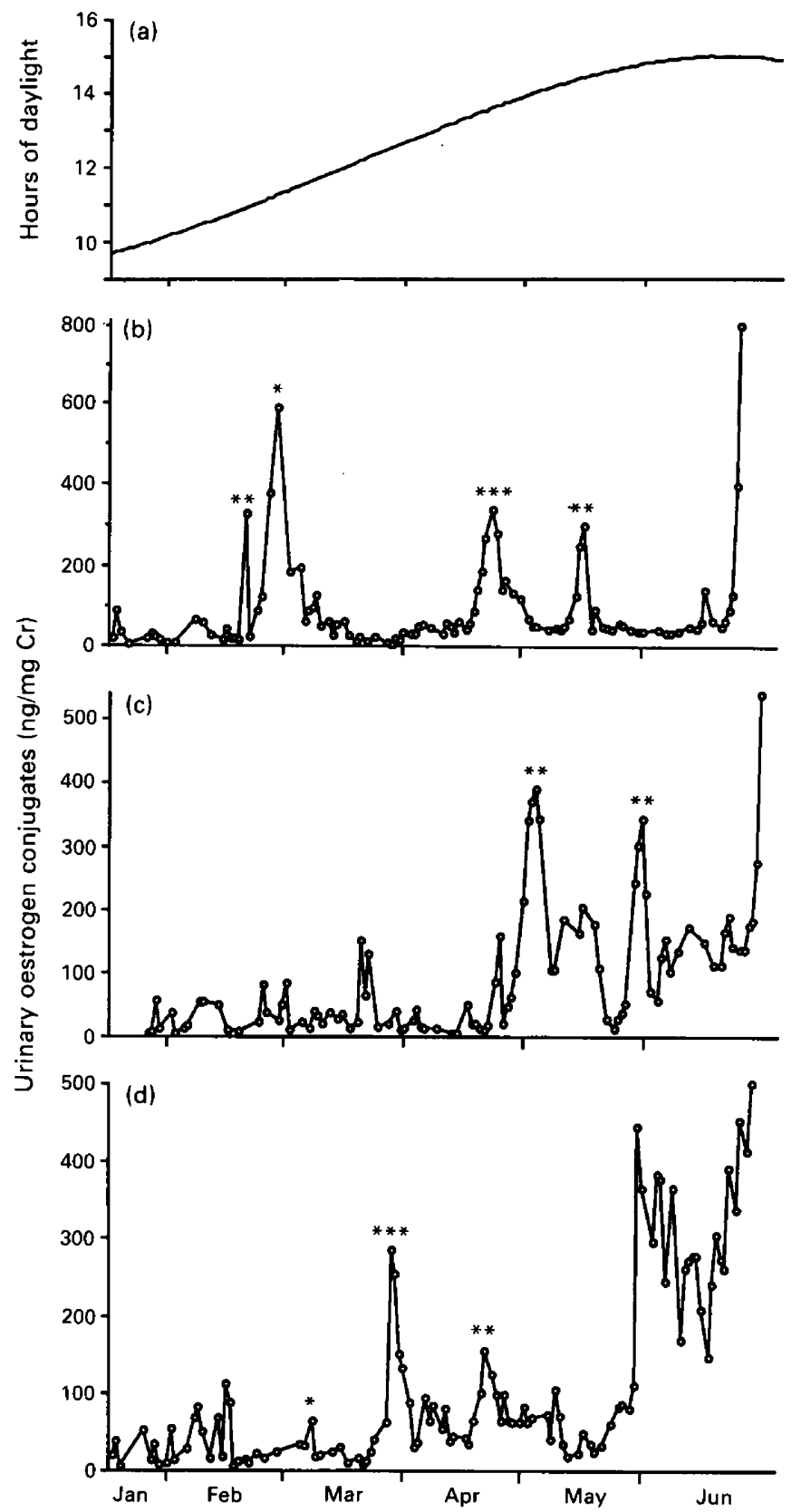

Fig. 2. Longitudinal profiles of urinary oestrogen conjugates from 3 Przewalski's mares (b-d) sampled from January to June during increasing daylengths (a). Asterisks indicate observed copulations.

conjugates values declined slightly $(P>0.05)$ to $0.10 \pm 0.02 \mu \mathrm{g} / \mathrm{mg} \mathrm{Cr}$ (Week -46 ; Fig. 4, inset), increased significantly to $0.46 \pm 0.05 \mu \mathrm{g} / \mathrm{mg} \mathrm{Cr}$ by Week -43 (6 weeks after the mid-cycle oestrogen conjugates peak; Fig. 4 , inset), rising an additional $\sim 200$-fold to peak pregnancy concentration of $101.90 \pm 34 \cdot 30 \mu \mathrm{g} / \mathrm{mg}$ Cr by Week -25 (51\% gestation). After the mid-pregnancy peak, weekly concentrations of oestrogen conjugates decreased steadily to $6.90 \pm 1.20 \mu \mathrm{g} / \mathrm{mg} \mathrm{Cr}$ by Week -1 and 


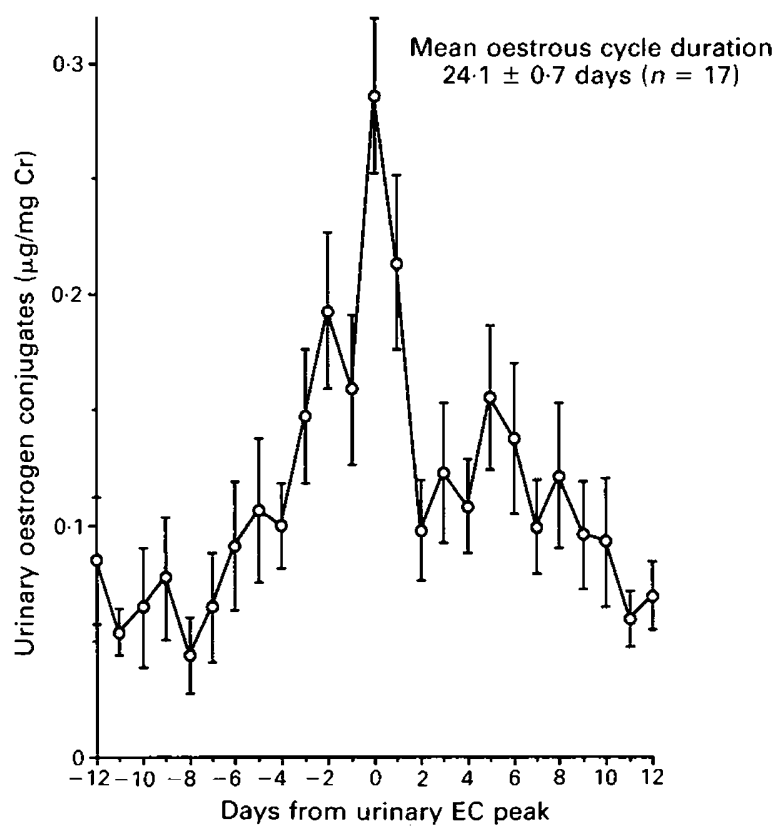

Fig. 3. Daily mean ( \pm s.e.m.) urinary oestrogen conjugates representing 17 oestrous cycles from 6 non-pregnant mares. Hormone values were aligned to the day of the urinary oestrogen conjugates $(\mathrm{EC})$ peak.

were not different from those of non-pregnant mares by Week +1 post partum $(0.09 \pm 0.02 \mu \mathrm{g} / \mathrm{mg}$ $\mathrm{Cr}, P>0.05)$. Urinary concentrations of oestrogen conjugates 1-2 days post partum ranged from 0.04 to $0.16 \mu \mathrm{g} / \mathrm{mg} \mathrm{Cr}$. Urine sampling frequency decreased during the post-partum interval because of nervous behaviour of the mares. None the less, there was evidence of possibly increased ovarian activity 10-14 days post partum in 3 mares based on increased oestrogen conjugates excretion. An example is the mare depicted in Fig. 5 which exhibited 2 non-conception ovarian cycles followed by a conception cycle and pregnancy. An irregular excretory pattern of oestrogen conjugates was observed post partum with metabolite concentrations achieving levels measured before conception.

\section{Discussion}

This study demonstrates the utility of longitudinal profiles of urinary oestrogen conjugates for studying reproductive seasonality and the endocrine events associated with cyclicity, pregnancy and parturition in the Przewalski's horse. Specifically, these data confirm that Przewalski's mares are seasonally polyoestrous with oestrous cycles commencing in the early spring. The failure of all mares to conceive during February and March suggests that the first seasonal oestrous periods in the Przewalski's horse may be anovulatory, like those in the domestic horse (Ginther, 1974). The finding that conception only occurred from April to November affirmed that this species has a potential breeding season of 7-8 months, which is similar to that of domestic horse (Ginther, 1974; Hughes et al., 1975) and donkey (Henry et al., 1987).

Chromatographic analsis revealed that, in general, conjugated forms of oestrone (oestrone sulphate and oestrone glucuronide) were the major excreted immunoreactive oestrogens in nonpregnant and pregnant Przewalski's mares. Almost half (46-6\%) of the excreted oestrogen immunoreactivity in oestrous mare urine was unconjugated oestrone/oestradiol. This contrasts with a 


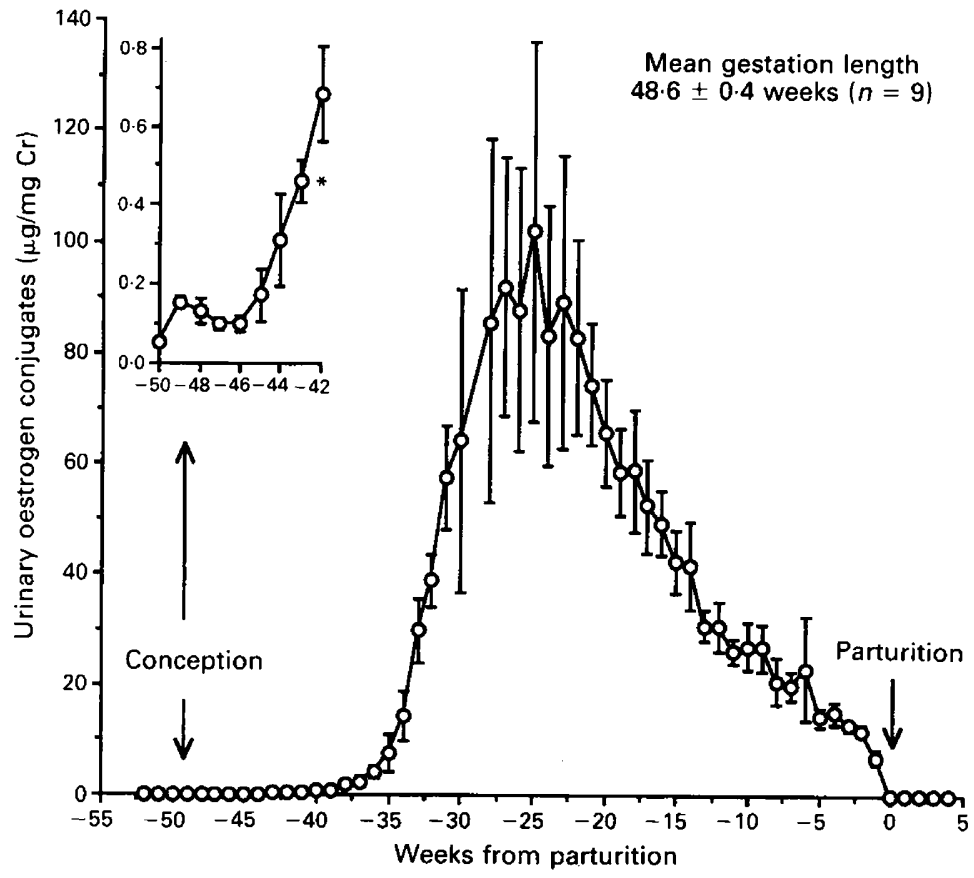

Fig. 4. Weekly mean ( \pm s.e.m.) urinary oestrogen conjugates representing 9 pregnancies monitored in 7 mares. Hormone values were aligned to the day of parturition. Inset: increase in urinary oestrogen conjugates around the time of conception: asterisk indicates significant increase in value in comparison to concentration in non-pregnant mares.

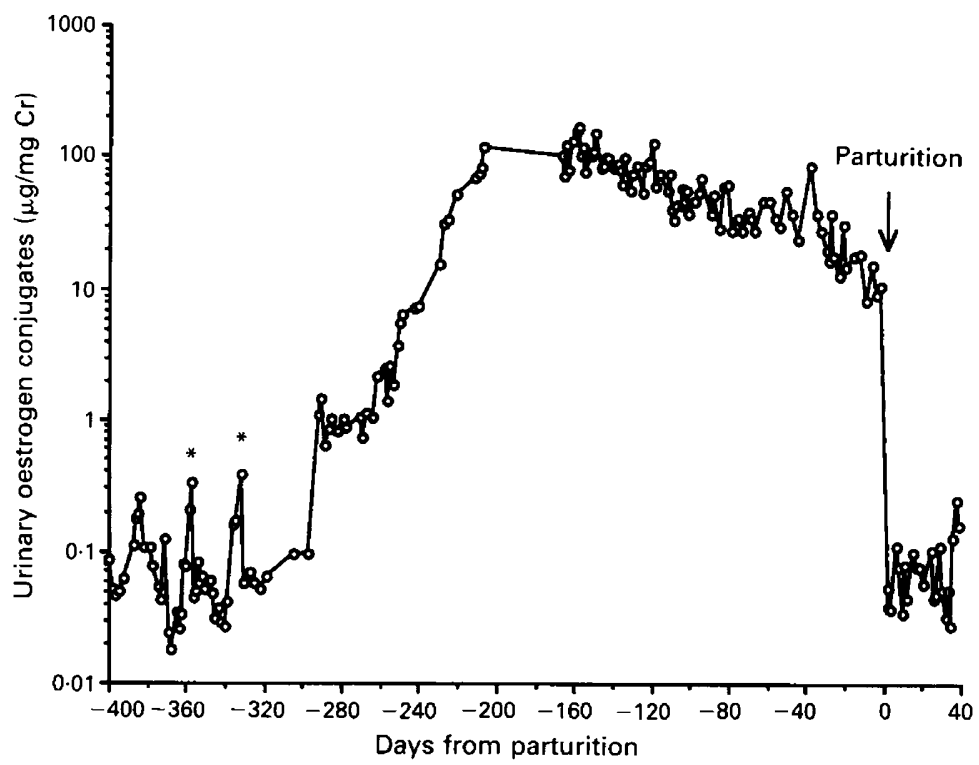

Fig. 5. Daily urinary excretion of oestrogen conjugates from a single mare sampled from 11 weeks before conception ( -400 days) until 6 weeks post partum $(+40$ days). Hormone values were aligned to the day of parturition. The vertical axis is presented on a logarithmic scale to facilitate identification of cyclic hormonal patterns. Asterisks denote observed copulations. 
report by Lasley et al. (1990) which indicated that $95 \%$ of the total oestrogen immunoreactivity in the domestic horse was contributed by oestrone sulphate. Unconjugated oestrone/oestradiol also accounted for a substantial proportion of the oestrogen immunoreactivity during the luteal phase $(\sim 20 \%)$ of the Przewalski's horse, although during pregnancy, oestrone/oestradiol excretion was diminished. During early pregnancy ( $\sim 40$ days), oestrone glucuronide was a major contributor $(\sim 43 \%)$ to total urinary oestrogen immunoreactivity. In contrast, at the same stage of gestation, oestrone glucuronide excretion contributes $<3 \%$ of total immunoreactivity detected in the domestic horse (Evans et al., 1984; Lasley et al., 1990). However, Heap et al. (1982) indicated that endometrial tissues of the latter species are capable of converting large quantities of radiolabelled oestrone to oestrone glucuronide $(34.0 \%)$ and oestrone sulphate $(43.6 \%)$ by $28-36$ days of gestation. Chromatographic separation revealed that $93-98 \%$ of excreted oestrogens at mid- and late gestation in the Przewalski's horse are in the form of oestrone sulphate, which further supports our assertion that oestrone is the dominant oestrogen of pregnancy in this species.

The estimated oestrous cycle length of $24 \cdot 1 \pm 0.7$ days was shorter than that reported for the donkey (25.4 days: Henry et al., 1987), but longer than that of the domestic horse (21.5 days: Back et al., 1974; 21.7 days: Hillman \& Loy, 1975; 20.6 days: Hughes et al., 1975). Mean urinary concentrations of oestrogen conjugates in the Przewalski's horse during the week preceding oestrus (dioestrus, $0 \cdot 04-0 \cdot 10 \mu \mathrm{g} / \mathrm{mg} \mathrm{Cr}$ ) and during oestrus itself $(0 \cdot 10-0 \cdot 29 \mu \mathrm{g} / \mathrm{mg} \mathrm{Cr}$ ) were in accord with previous values reported by Czekala et al. (1990) for this species. The domestic horse excretes more conjugated oestrogens during dioestrus $(0 \cdot 13-0.15 \mu \mathrm{g} / \mathrm{mg} \mathrm{Cr})$ and oestrus $(0 \cdot 35-0.47 \mu \mathrm{g} / \mathrm{mg} \mathrm{Cr})$ (Evans et al., 1984) than does the Przewalski's horse. Despite quantitative differences, the temporal interrelationships between copulatory behaviour and rising oestrogen excretion levels were similar between the Przewalski's and domestic (Munro et al., 1979) mares.

Urinary concentrations of oestrogen conjugates were elevated markedly by the 6th week of gestation which was the earliest time that a potential pregnancy could be diagnosed accurately. This excretion profile was comparable to that of the domestic horse (Evans et al., 1984; Lasley et al., 1990). In the domestic horse, the sharp increase in urinary oestrogen excretion between 30 and 40 days of gestation appears to reflect increased ovarian activity in response to chorionic gonadotrophin (CG) secreted by the trophoblast (Lasley et al., 1990). Our observations suggest that similar mechanisms may exist in the Przewalski's horse. Because endometrial cups can produce CG in the absence of a fetus (Cole \& Goss, 1943), increased urinary excretion of oestrogen conjugates only indicates an attempt to establish pregnancy. Therefore, urinary concentrations of oestrogen conjugates may not reflect actual fetal presence and viability until after endometrial cup production of CG ceases at about 90 days of gestation (Lasley et al., 1990).

Our finding of a gestation length of 48.6 weeks agrees well with estimates reported by Boyd (1988) for this species. The temporal patterns of oestrogen conjugates throughout pregnancy were analogous to the findings of Czekala et al. (1990) who examined composite profiles from different mares sampled once or twice during gestation. However, we observed peak urinary concentrations of oestrogen conjugates which exceeded $100 \mu \mathrm{g} / \mathrm{mg} \mathrm{Cr}$, and these concentrations were $25-50 \%$ higher than the maximal levels measured by Czekala et al. (1990). Peak urinary excretion of oestrogens in the domestic horse occurs at 6-7 months of gestation (Raeside \& Liptrap, 1975; Nett et al., 1975), which is about 30 days later than in the Przewalski's mare (5-6 months). However, in animals of both species there is a rapid decline in oestrogen excretion after mid-pregnancy with the decrease becoming more gradual as parturition approaches. The marked increase and subsequent decline in oestrone secretion during pregnancy in the domestic horse parallels fetal gonadal development and regression (Pashen \& Allen, 1979; Pashen et al., 1982).

From a conservation and management perspective, our results indicate that longitudinal reproductive events can be monitored precisely by evaluating urinary oestrogen conjugates in samples collected from captive Przewalski's mares maintained under semi-free-ranging conditions. Longitudinal sample collection under field conditions is time-consuming, but provides an effective, non-invasive method for diagnosing pregnancy. Although this approach may not permit tracking 
fetal viability until $\sim 25 \%$ gestation, we detected no false positives $(n=9)$ in our study. For field diagnosis of pregnancy, we speculate that as few as 3 urine samples collected over a 2-week interval are necessary to predict pregnancy accurately. When stallions are interchanged in an effort to enhance genetic diversity within breeding herds, information on pregnancy status can be used to help prevent infanticide which occurs in this species. We presently perform pregnancy checks before introducing new stallions to the breeding herd, and pregnant mares are removed to a nursery herd for foaling. Finally, longitudinal monitoring of urinary oestrogen metabolites, including prediction of ovulation, could be extremely useful in conjunction with artificial insemination, ovulation induction and embryo recovery. These techniques could be particularly important for ensuring reproduction between valuable but behaviourally incompatible pairs and eliminate the risks inherent in transporting animals between breeding facilities.

We thank Dr Christen Wemmer, Dr Mitchell Bush and Larry Collins for advice and logistical support; and the animal keeper staff, including Tracy Kepler, Ken Lang, Caroline Martinet, Pamela Starkey, Lauren Wemmer, and the many volunteers at the Conservation and Research Center for assisting with collection of urine samples and performance of assays. This research was funded by grants from the Scholarly Studies Program of the Smithsonian Institution, the Friends of the National Zoo and the Women's Committee of the Smithsonian Associates.

\section{References}

Back, D.G., Pickett, B.W., Voss, J.L. \& Seidel, G.E. (1974) Observations on the sexual behavior of nonlactating mares. J. Am. vet. med. Assoc. 165, 717-720.

Bowling, A.T. \& Ryder, O.A. (1987) Genetic studies of blood markers in Przewalski's horses. J. Hered. 78, $75-80$.

Boyd, L. (1988) The behavior of the Przewalski's horse. Ph.D. Dissertation, Cornell University, Ithaca, NY.

Cole, H.H. \& Goss, H. (1943) The source of equine gonadotrophin. In Essays in Biology in Honor of Herbert M. Evans, pp. 107-119. University of California Press, Berkeley.

Czekala, N.M., Kasman, L.H., Allen, J., Oosterhuis, J. \& Lasley, B.L. (1990) Urinary steroid evaluations to monitor ovarian function in exotic ungulates. VI. Pregnancy detection in exotic Equidae. Zoo Biol. 9, 43-48.

Evans, K.L., Hughes, J.P., Couto, M., Kasman, L.H. \& Lasley, B.L. (1984) Pregnancy diagnosis in the domestic horse through direct urinary estrone conjugate analysis. Theriogenology 22, 615-620.

Ginther, O.J. (1974) Occurrence of anestrus, estrus, diestrus, and ovulation over a 12 -month period in mares. Am. J. vet. Res. 35, 1173-1179.

Heap, R.B., Hamon, M. \& Allen, W.R. (1982) Studies on oestrogen synthesis by the preimplantation equine conceptus. J. Reprod. Fert., Suppl. 32, 342-352.

Hearn, J.P. \& Summers, P.M. (1986) Experimental manipulation of embryo implantation in the marmoset monkey and exotic equids. Theriogenology 25, $3-11$.

Heikkinen, R., Fotsis, T. \& Adlercreutz, H. (1981) Reversed-phase $\mathrm{C} 18$ cartridge for extraction of estrogens from urine and plasma. Clin. Chem. 27, $1186-1189$.

Henry, M., Figueiredo, A.E.F., Palhares, M.S. \& Coryn, M. (1987) Clinical and endocrine aspects of the oestrous cycle in donkeys (Equus asinus). J. Reprod. Fert., Suppl. 35, 297-303.
Hillman, R.B. \& Loy, R.G. (1975) Oestrogen excretion in mares in relation to various reproductive states. $J$. Reprod. Fert., Suppl. 23, 223-230.

Hughes, J.P., Stabenfeldt, G.H. \& Evans, J.W. (1975) The oestrous cycle of the mare. J. Reprod. Fert., Suppl. 23, 161-166.

Kirkpatrick, J.F., Kasman, L.H., Lasley, B.L. \& Turner, J.W. (1988) Pregnancy determination in uncaptured feral horses. J. Wildl. Mgt 52, 305-308.

Lasley, B., Ammon, D., Daels, P., Hughes, J., Munro, C. \& Stabenfeldt, G.H. (1990) Estrogen conjugate concentrations in plasma and urine reflect estrogen secretion in the nonpregnant and pregnant mare: a review. Eq. vet. Sci. 10, $1-4$.

Monfort, S.L., Dahl, K.D., Czekala, N.M., Stevens, L., Bush, M. \& Wildt, D.E. (1989) Monitoring ovarian function and pregnancy in the giant panda (Ailuropoda melanoleuca) by evaluating urinary bioactive FSH and steroid metabolites. J. Reprod. Fert. 85, 203-212.

Monfort, S.L., Wemmer, C., Kepler, T.H., Bush, M., Brown, J.L. \& Wildt, D.E. (1990) Monitoring ovarian function and pregnancy in Eld's deer (Cervus eldi thamin) by evaluating urinary steroid metabolite excretion. J. Reprod. Fert. 88, 271-281.

Munro, C.D., Renton, J.P. \& Butcher, R. (1979) The control of oestrous behaviour in the mare. J. Reprod. Fert., Suppl. 27, 217-227.

Nett, T.M., Holtan, D.W. \& Estergreen, V.L. (1975) Oestrogens, LH, PMSG and prolactin in serum of pregnant mares. J. Reprod. Fert., Suppl. 23, 457-462.

Palmer, E. \& Jousset, B. (1975) Urinary oestrogen and plasma progesterone levels in non-pregnant mares. $J$. Reprod. Fert., Suppl. 23, 213-221.

Pashen, R.L. \& Allen, W.R. (1979) The role of the fetal gonads and placenta in steroid production, maintenance of pregnancy and parturition in the mare. $J$. Reprod. Fert., Suppl. 27, 499-509. 
Pashen, R.L., Sheldrick, E.L., Allen, W.R. \& Flint, A.P.F. (1982) Dehydroepiandrosterone synthesis by the fetal foal and its importance as an oestrogen precursor. J. Reprod. Fert., Suppl. 32, 389-397.

Raeside, J.I. \& Liptrap, R.M. (1975) Patterns of urinary oestrogen excretion in individual pregnant mares. $J$. Reprod. Fert., Suppl. 23, 469-475.

Ryder, O.A. (1988) Przewalski's horse-Putting the wild horse back in the wild. Oryx 22, 154-157.

Shideler, S.E., Czekala, N.M., Kasman, L.H., Lindburg, D.G. \& Lasley, B.L. (1983) Monitoring ovulation and implantation in the lion-tailed macaque (Macaca silenus) through urinary estrone conjugate evaluation. Biol. Reprod. 29, 905-911.

Short, R.V (1975) The evolution of the horse. J. Reprod. Fert., Suppl. 23, 1-6.

Taussky, H.H. (1954) A microcolorimetric determination of creatinine in urine by the Jaffe reaction. $J$. biol. Chem. 208, 853-861.

Velle, W. (1963) Metabolism of estrogenic hormones in domestic animals. Gen. comp. Endocr. 3, 621-625.

Received 4 April 1990 